\title{
Neural Correlates of human cognitive abilities during sleep
}

\author{
Fang, Zhuo ${ }^{1}$, Ray, Laura B. ${ }^{1,4}$, Owen, Adrian M. ${ }^{1,2}$, \& Fogel, Stuart M. ${ }^{1-5 *}$.
}

1. Brain \& Mind Institute, Western University, London, Canada, 2. Department of Psychology, Western University, London, Canada, 3. School of Psychology, University of Ottawa, Ottawa, Canada, 4. University of Ottawa Institute for Mental Health Research, Ottawa, Canada, 5. University of Ottawa Brain and Mind Research Institute, Ottawa, Canada.

\section{Corresponding author:}

Dr. Stuart M. Fogel

Assistant Professor

School of Psychology

Director, Sleep Neuroscience

University of Ottawa Institute for Mental Health Research

University of Ottawa

Ottawa, Ontario, Canada

(613) $562-5800 \times 4295$

sfogel@uottawa.ca

socialsciences.uottawa.ca/sleep-lab/ 
1 Inter-individual differences in sleep spindles are highly correlated with "Reasoning" abilities

2 (problem solving skills; i.e., the ability to employ logic, identify complex patterns), but not Short

3 Term Memory or Verbal abilities. Simultaneous electroencephalography and functional

4 magnetic resonance imaging (EEG-fMRI) have revealed brain activations time-locked to

5 spindles (e.g., thalamic, paralimbic, and motor cortical areas)-yet the functional significance of

6 inter-individual differences in spindle-related brain activation remains to be investigated. Using

7 EEG-fMRI during sleep, we identified, for the first time, the neural activation patterns time-

8 locked to spindles that are correlated with cognitive abilities. Similar to previous studies,

9 activations time-locked to spindles were observed in thalamocortical circuitry and basal ganglia regions. Importantly, spindle-related activation in a subset of these regions were specifically

11 related to inter-individual differences in Reasoning, but not STM or Verbal abilities. These results may help elucidate the physiological mechanisms which support the function of sleep for the capacity for reasoning.

14 Keywords: sleep, spindles, cognitive abilities, simultaneous EEG-fMRI 


\section{INTRODUCTION}

The sleep spindle is the only known spontaneous neural oscillation that has been identified as an electrophysiological marker of cognitive abilities and aptitudes, that are typically assessed by intelligence quotient (IQ) tests (for review, see Fogel \& Smith, 2011). As one of the defining features of Stage 2 non-rapid eye movement (NREM) sleep, spindles are traditionally defined as neural oscillations between 11 and $16 \mathrm{~Hz}$ (Iber et al., 2007), lasting up to $\sim 3 \mathrm{sec}$ in duration (Rechtschaffen \& Kales 1968). Spindles are remarkably stable from night-to-night, but vary considerably from one individual to another, and have even been suggested to be an "electrophysiological fingerprint" (De Gennaro et al., 2005) because of the trait-like nature of spindles(Silverstein \& Michael Levy, 1976). Previous studies have revealed that interindividual differences in spindle characteristics are related to the capacity for reasoning (i.e., the ability to identify complex patterns and relationships, the use of logic, existing knowledge, skills, and experience to solve novel problems (Fogel \& Smith, 2007; Fogel \& Smith, 2006; Nader \& Smith, $2001,2003)$. Moreover, the relationship between spindles and cognitive abilities is specific to the capacity for Reasoning, over-and-above Verbal abilities and short-term memory(Fang et al., 2017; Fogel et al., 2007). These studies have provided insight into the electrophysiological correlates of Reasoning abilities, insofar as to suggest that efficient functioning of the neural substrates that support spindle generation (e.g., thalamocortical circuitry) may be related to the capacity for these cognitive skills. Interestingly, spindle production is reduced with age (Carrier et al., 2001; Fogel et al., 2014; Fogel et al., 2017), and abnormal in developmental disorders, such as Autism (Limoges et al., 2005), learning disabilities (Shibagaki et al., 1982) and in schizophrenia (Wamsley et al., 2012). Thus, a better understanding of the neural basis of the relationship between spindles and cognitive abilities may ultimately help to better understand the significance to a variety of normal and abnormal cognitive functioning in healthy individuals 
and in neurological conditions. This may eventually lead to novel interventions to precisely target cases where spindle production is abnormal or non-optimal. However, it is necessary to first understand the physiological correlates of the relationship between spindles and Reasoning abilities in healthy individuals, which is the principle aim of the current study.

The association between sleep spindles and individual differences in cognitive abilities has been well documented. For example, Nader and Smith (Fogel \& Smith, 2006; Nader \& Smith, $2001,2003)$ found that both the number of sleep spindles and sigma power $(12-14 \mathrm{~Hz})$ uniquely correlated with Performance IQ scores, over-and-above Verbal IQ (Fogel et al., 2007). Consistently, Bodizs and colleagues (Bódizs et al., 2005) found that spindle density was correlated with Reasoning abilities (i.e., "fluid intelligence") measured by the Raven's Progressive Matrices (Raven, Court, and Raven 1976). Similar studies identified a positive correlation between right-parietal fast spindles and visuospatial abilities assessed by the ReyOsterrieth Complex Figure test (Bódizs et al., 2008), and a positive correlation between spindles and the intellectual abilities measured by the Cattell Culture Fair Intelligence Test, specifically in woman but not in men (Ujma et al., 2014). Although, a relationship in men was subsequently identified by the same group in daytime sleep (Ujma et al., 2015). Most recently, Fang and colleagues (Fang et al., 2017) used the Cambridge Brain Sciences (CBS) test battery (Hampshire et al., 2012) to explore if the relationship between sleep spindles and intellectual ability was a direct relationship, or whether this could be partially (or fully explained) by other spindle-related factors such as sleep quality or circadian chronotype. They found that, indeed, the relationship between spindles and Reasoning abilities was independent of sleep quality and circadian chronotype. Taken together, these studies support the notion that sleep spindles are an electrophysiological marker of cognitive abilities, and specifically, the ability to solve 
62

problems using logic and reasoning. However, the brain regions supporting the relationship between the sleep spindles and cognitive abilities are still unknown.

Only a small number of studies have employed simultaneous electroencephalography and functional magnetic resonance imaging (EEG-fMRI) to explore brain activations time-locked to spindles (Andrade et al., 2011; Caporro et al., 2012; Laufs et al., 2007; Schabus et al., 2007; Tyvaert et al., 2008). Spindle-related activations have been consistently found in the thalamus and the temporal lobe, for both fast spindles and slow spindles (Andrade et al., 2011; Caporro et al., 2012; Laufs et al., 2007; Schabus et al., 2007; Tyvaert et al., 2008), and activation of the cingulate cortex and motor areas have been reported to be associated with sleep spindles during NREM sleep (Andrade et al., 2011; Caporro et al., 2012). Interestingly, activation of the putamen has also been found to be correlated with spindle events (Caporro et al., 2012; Tyvaert et al., 2008) and Andrade et al. (2011) found a strong interaction between sleep spindle occurrence and hippocampal formation functional connectivity. In addition, by directly comparing fast spindles vs. slow spindles, Schabus et al. (2007) observed that slow spindles increase activations in the superior temporal gyrus while fast spindles recruit activations in the sensorimotor area, mesial frontal cortex, hippocampus, and cerebellum. Not surprisingly, given the methodological complexities and limitations of EEG-fMRI recordings during sleep, most of these studies used relatively small sample sizes $(n<15)$, suggesting that additional studies investigating the neural correlates of sleep spindles in a larger sample is warranted. Nonetheless, taken together, the extant literature intriguingly suggest that brain activations associated with the action of sleep spindles involve well-known spindle-generating regions (e.g., thalamic and cortical regions), as well as regions which subserve cognitive functioning and memory (e.g., hippocampal, striatal, prefrontal, motor cortical and cerebellar regions). 
Interestingly, some of the regions activated during spindle events, are thought to support

human cognitive abilities. For example, the thalamocortical circuitry, one of the most important neural substrates related to spindle generation (Steriade, Contreras et al.,1993; Steriade, McCormick, \& Sejnowski, 1993), has been observed to be involved in reasoning abilities assessed by Raven's Progressive Matrices test (Gray et al., 2003), the Wechsler Adult Scale of Intelligence (WAIS-III) (Wecshler, 1997), and other reasoning ability-related tasks, especially with regard to the prefrontal cortex and the thalamus (Bugg et al., 2006; Kroger, 2002; Melrose, Poulin, \& Stern, 2007; Waltz et al., 1999). In addition, the basal ganglia region, especially the striatal areas (i.e. caudate and putamen), which are recruited during spindle events (Caporro et al., 2012; Tyvaert et al., 2008), have also been found to be related to cognitive functions, including reward-based learning (O'Doherty, 2004), planning (Elsinger et al., 2006), motor execution (Monchi et al., 2006), and reasoning (Melrose et al., 2007; Rodriguez-Moreno \& Hirsch, 2009). Recently, Hampshire et al. (2012) employed the Cambridge Brain Sciences cognitive test battery to identify and distinguish the brain networks that support distinct cognitive abilities (e.g., Reasoning, Verbal, and Short Term Memory). It was found that the inferior frontal sulcus, the inferior parietal cortex, and the dorsal portion of the anterior cingulate I supplementary motor area activations related to Reasoning abilities and were disassociated from brain regions that related to Verbal abilities and Short Term Memory. While it is intriguing that a subset of regions which support Reasoning abilities are also regions activated with the occurrence of sleep spindles, it remains to be investigated whether spindle-related activations in these areas are correlated with interindividual differences in Reasoning abilities.

Thus, it is clear that spindle characteristics are linked to Reasoning abilities, however, the neural correlates of this relationship remain unknown. Therefore, here, using a large sample of simultaneous EEG-fMRI recordings during sleep, we sought to identify, for the first time, the 
neuroanatomical function correlates of the relationship between sleep spindles and Reasoning

110 abilities. We hypothesized that the neural activation patterns, time-locked to spindles would be

111 related to distinct cognitive abilities whereby consistent with previous cognitive and

112 electrophysiological studies, spindle-related brain activations would be correlated with

113 Reasoning but not STM or Verbal abilities. This will provide insight into the neural basis of the

114 functional correlates of sleep spindles.

\section{RESULTS}

116 Cognitive abilities: Cambridge Brain Sciences Trials

12 subtests were Z-score normalized using the mean and standard deviation of each subtest from a large population $(N=44,600)$. Each test item was then weighted according to the factor loadings from Hampshire et al. (Hampshire et al., 2012) and then the respective sub-tests were averaged to create the Reasoning, STM and Verbal sub-scores and transformed to a mean of 100 and a SD of 15 , so that test scores were readily comparable to results from similar studies

123 that employed test batteries tapping into Reasoning and Verbal abilities, such as the Multidimensional Aptitude Battery - II (Fogel et al., 2007; Fogel \& Smith, 2006) and other

125 commonly used batteries of cognitive abilities (e.g., Wechsler Adult Intelligence Scale). The 
Table 1. Descriptive statistics of the 3 CBS Trials subscales (Reasoning, Short-term memory (STM) and Verbal abilities).

\begin{tabular}{llll}
\hline IQ Measures & Range & Mean \pm SD & Median \\
\hline Reasoning & $78.84-108.17$ & $95.65 \pm 7.20$ & 96.46 \\
STM & $84.38-115.33$ & $101.60 \pm 6.77$ & 102.30 \\
Verbal & $88.51-110.92$ & $99.62 \pm 5.12$ & 99.52 \\
\hline
\end{tabular}

\section{Sleep Architecture:}

Participants slept, on average, a total of 44.20 (SD=23.84) minutes in the scanner during the experimental sleep session (Table 2). All N=29 participants experienced NREM2 sleep, $\mathrm{N}=20$ had SWS sleep, and N=8 had rapid eye movement (REM) sleep. Given the focus of the current investigation, we did not analyze REM data. Participants had on average, a total of $334.74(\mathrm{SD}=212.29)$ total bandwidth sleep spindles at $\mathrm{Cz}$ during NREM sleep. Spindle parameters for all spindles at $\mathrm{Cz}(11-16 \mathrm{~Hz})$, slow spindles at $\mathrm{Fz}(11-13.5 \mathrm{~Hz})$ and fast spindles at Pz (13.5-16 Hz) during NREM sleep are shown in the Table 2.

7

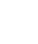


Table 2. Sleep architecture and sleep spindle parameters for spindles at $\mathrm{Fz}, \mathrm{Cz}$ and $\mathrm{Pz}$ during NREM sleep from EEG-fMRI recording sessions.

M

SD

Sleep Architecture

Wake (min)

NREM1 (min)

NREM2 (min)

SWS (min)

NREM (min)

REM

Total Sleep

Number

Duration (sec)

Amplitude $(\mu \mathrm{V})$

Density

Number

Duration (sec)

Amplitude $(\mu \mathrm{V})$

Density

Number

Duration (sec)

Amplitude $(\mu \mathrm{V})$

Density
26.87

20.25

5.84

23.87

14.77

39.29

17.80

44.20

Total bandwidth (11-16 Hz) spindles at $\mathrm{Cz}$

334.74

212.29

0.49

0.05

27.21

6.43

8.22

2.34

Slow spindles (11-13.5 Hz) at Fz

249.41

179.40

0.38

0.06

42.71

9.44

6.00

2.20

Fast (13.5-16 Hz) spindles at Pz

92.48

69.66

0.38

0.08

21.53

6.01

2.50

1.80

Abbreviations: non-rapid eye movement sleep (NREM); stage 1 sleep (NREM1); stage 2 sleep (NREM2); slow wave sleep (SWS); rapid eye movement sleep. 


\section{Relationship between sleep spindles and cognitive abilities}

Standard multiple linear regression revealed that, taken together, Reasoning, Short Term

Memory and Verbal abilities significantly accounted for variability in spindle amplitude $(F(3,25)$

$\left.=4.884, r^{2}=0.370, p=0.008\right)$, but not duration $\left(F(3,25)=0.531, r^{2}=0.060, p=0.665\right)$ or

149 density $\left(F(3,25)=2.522, r^{2}=0.232 p=0.081\right)$ at $C z$ during NREM sleep (Table 3). Similar to previous studies (Fang et al., 2017; Fogel et al., 2007), inspection of the semipartial coefficients

revealed that Reasoning ability $(\mathrm{t}(25)=2.191, r=0.401, \mathrm{p}=0.038$; Figure 1 ) uniquely accounted for variability in spindle amplitude over and above STM $(t(25)=0.314, r=0.063, p$ $=0.756)$ and Verbal $(t(25)=0.972, r=0.191, p=0.341)$ abilities. The same regression analyses were conducted for slow spindles at Fz and fast spindles at Pz, however, we did not observe any significant relationship between spindles and cognitive abilities.

Table 3. Multiple regression analyses of the relationship between Cambridge Brain Sciences Trials and $11-16 \mathrm{~Hz}$ spindles at Cz during NREM sleep. See Figure 1.

\section{Overall regression effect}

\begin{tabular}{lccc} 
Sleep Spindle parameter & $\mathbf{r}^{2}$ & $\mathbf{F}(\mathbf{3}, \mathbf{2 5})$ & $\mathbf{p}$ \\
Amplitude & 0.37 & 4.884 & $0.008^{*}$ \\
Duration & 0.060 & 0.531 & 0.665 \\
Density & 0.232 & 2.522 & 0.081 \\
& & Post-hoc effects analyses & \\
CBS measures & Semipartial $\mathbf{r}$ & $\mathbf{t}(\mathbf{2 5})$ & $\mathbf{p}$ \\
Reasoning & 0.401 & 2.191 & $0.038^{*}$ \\
Verbal & 0.191 & 0.972 & 0.341 \\
STM & 0.063 & 0.314 & 0.756 \\
\hline
\end{tabular}




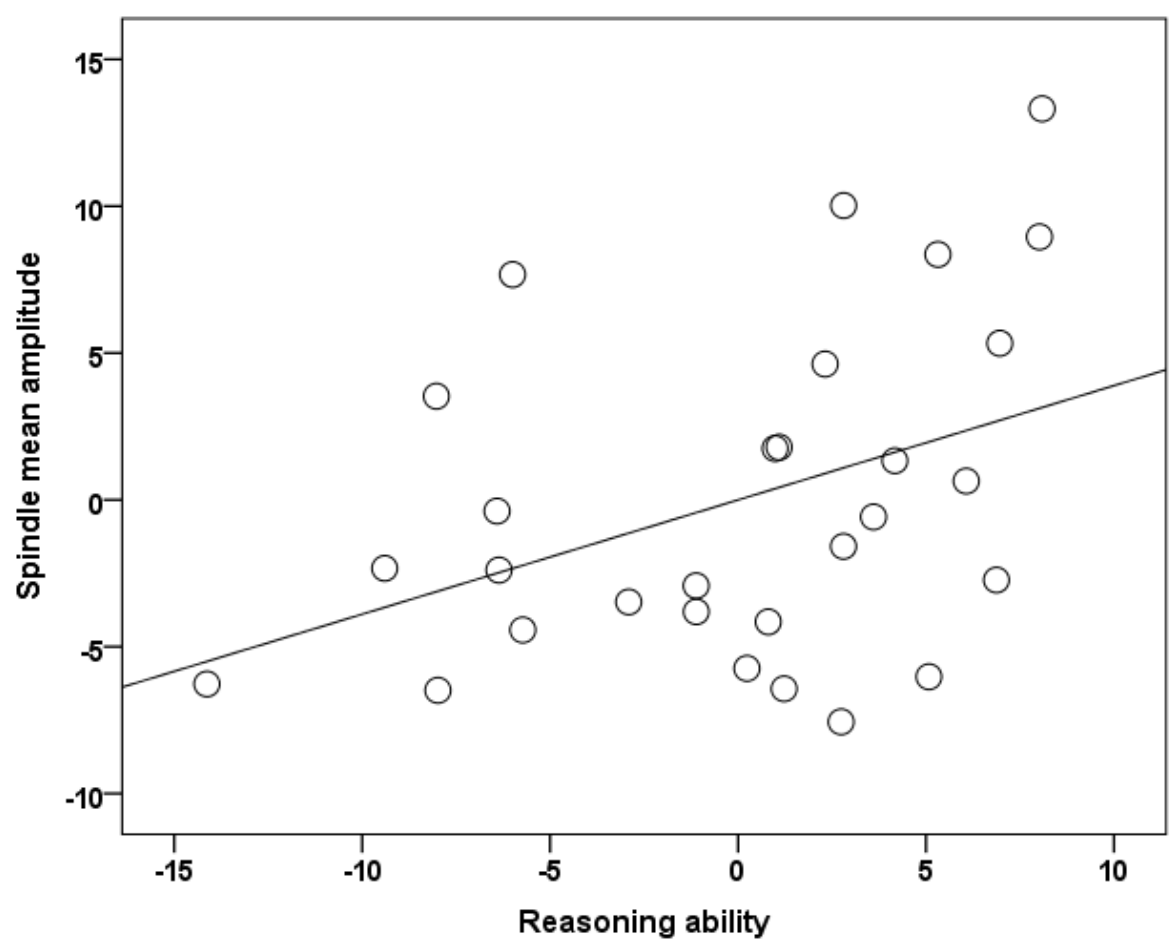

Figure 1. The unique relationship (i.e., semipartial correlation, $r(29)=0.401, p=0.038$ ) between Reasoning ability, over-and-above STM and Verbal abilities with spindle amplitude during NREM2.

\section{Activation of brain regions time-locked to spindles during NREM sleep}

As shown in Figure 2A, activations time-locked to all spindles (11-16 Hz) at $\mathrm{Cz}$ during NREM sleep, were observed in the thalamus/midbrain, the bilateral striatum (putamen/globus pallidum and caudate), the medial frontal cortex, cerebellum, and the brain stem (cluster-level FWE corrected $p<0.05$, Table 4). These results were statistically robust, as it is worth noting that even when a conservative whole-brain voxel-wise FWE statistical threshold correction ( $p$ $<0.05)$ was used, activations remained statistically significant in the thalamus/midbrain, the brainstem, the cerebellum, and the right putamen. 


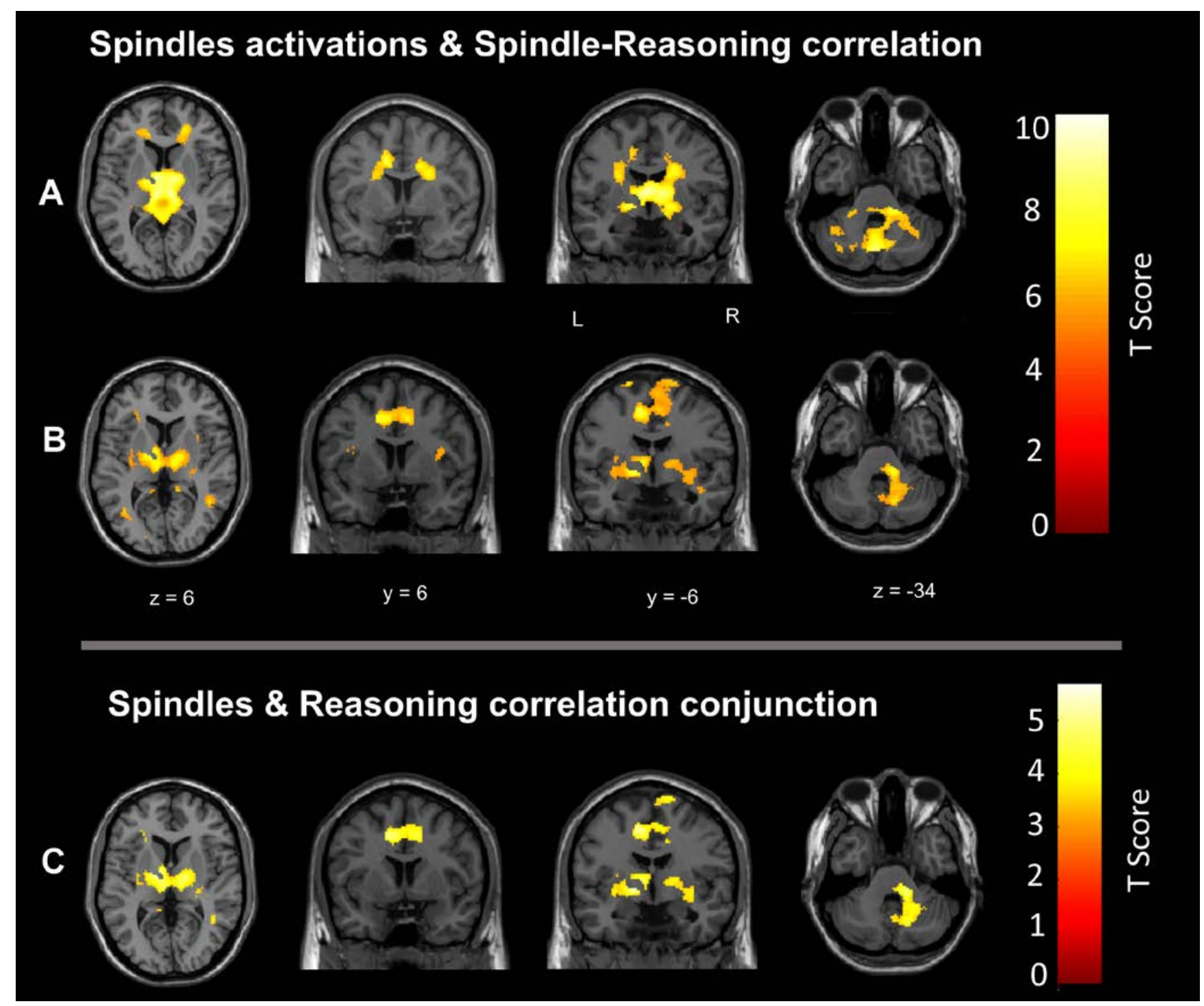

171

Figure 2. Cerebral activation time-locked to sleep spindles and correlation between spindle-related activation and Reasoning abilities. A. Activations time-locked to sleep spindles per se during NREM sleep. B. Spatial correlation maps between activations time-locked to sleep spindles and Reasoning abilities. C. Conjunction between $A$ and $B$.

Given the two physiologically distinct spindles types (fast and slow), we also explored the brain activations time-locked to fast (13.5-16 Hz) spindles and slow (11-13.5 Hz) spindles during NREM sleep. As shown in Figure S1, activations time-locked to fast spindles at Pz (Figure S1A) and slow spindles at Fz (Figure S1B) were very similar in most brain regions, including the thalamus, the precuneus, and the cerebellum. There were no significant differences between fast spindle and slow spindle-related activations. 
Table 4. Statistically significant activations time-locked to $11-16 \mathrm{~Hz}$ sleep spindles at $\mathrm{Cz}$ during NREM sleep (see Figure 2A).

\begin{tabular}{llrrrrr}
\hline & & \multicolumn{2}{c}{ MNI Coordinate } & \multicolumn{2}{c}{ Peak Z } & FWE corrected \\
Hemisphere & Region & $\mathbf{X}$ & \multicolumn{1}{c}{$\mathbf{Y}$} & $\mathbf{Z}$ & score & p-value \\
\hline Right & thalamus & 10 & -22 & 12 & 6.47 & $<0.001$ \\
Left & thalamus & -12 & -26 & 16 & 6.00 & $<0.001$ \\
Left & caudate & -14 & 12 & 12 & 6.07 & $<0.001$ \\
Left & putamen/pallidum & -18 & -2 & -4 & 4.22 & 0.001 \\
Right & putamen/pallidum & 18 & -4 & -4 & 5.32 & $<0.05$ \\
Bilateral & cerebellum & 2 & -62 & -10 & 5.88 & $<0.001$ \\
Left & anterior cingulate & -16 & 32 & 18 & 5.16 & 0.001 \\
Right & anterior cingulate & 12 & 22 & 28 & 3.94 & 0.001 \\
Middle & middle cingulate & 0 & 24 & 32 & 4.53 & 0.001 \\
\hline
\end{tabular}

Note: Significant brain responses after Family Wise Error (FWE) correction $p<0.05$ at the clusterlevel.

184 Correlation between cognitive abilities and brain activations time-locked to spindles

185
To examine the neural correlates of the relationship between sleep spindles and cognitive abilities, we conducted whole-brain spatial correlation analyses between brain activation maps time-locked to all spindles at Cz and the scores on the three cognitive factors (Reasoning, STM, and Verbal abilities) assessed by the Cambridge Brain Sciences tests. As shown in Figure 2B, Reasoning ability was significantly correlated with spindle-related activation maps in the thalamus, bilateral putamen, brainstem/pons anterior cingulate cortex, the middle cingulate cortex, the paracentral lobe, the posterior cingulate cortex, the precuneus, and bilateral temporal lobe (see Table 5). 
Table 5. Whole brain correlations between Reasoning ability and $11-16 \mathrm{~Hz}$ spindle-related activations at Cz during NREM sleep. (see Figure 2B)

\begin{tabular}{llrrrrr}
\hline & & \multicolumn{2}{c}{ MNI Coordinate } & \multicolumn{2}{c}{ Peak z } & FWE corrected \\
Hemisphere & Region & X & Y & Z & score & p-value \\
\hline Left & paracentral lobe & -12 & -32 & 58 & 5.01 & $<0.001$ \\
Middle & anterior cingulate & -6 & 12 & 26 & 4.44 & $<0.001$ \\
Middle & middle cingulate & -8 & 10 & 40 & 4.07 & $<0.001$ \\
Left & Precuneus & -14 & -58 & 32 & 5.12 & $<0.001$ \\
Left & putamen/pallidum & -16 & -6 & -2 & 4.39 & $<0.001$ \\
Right & putamen & 32 & -6 & -8 & 3.38 & $<0.001$ \\
Left & thalamus & -12 & -10 & 6 & 4.18 & $<0.001$ \\
Right & thalamus & 16 & -10 & 8 & 4.03 & $<0.001$ \\
Right & cerebellum & 14 & -64 & -34 & 3.80 & $<0.001$ \\
Left & temporal lobe & -42 & -58 & -2 & 4.30 & $<0.05$ \\
Right & temporal lobe & 48 & -52 & -4 & 4.24 & $<0.05$ \\
\hline
\end{tabular}

Note: Significant brain responses after Family Wise Error (FWE) correction $p<0.05$ at the clusterlevel.

for by Verbal or STM abilities, we also examined the correlations between spindle-related 
207 spindles. The same whole-brain spatial correlation analyses were conducted for fast spindle

208 and slow spindle activation maps, however, we did not observe significant correlations between 209 any cognitive ability and the activation maps for each individual spindle type.

From Figure 2, we can see that there were several overlapping regions between the

spindle activation maps (Figure 2A) and the maps that show activations time-locked to spindles

212 that were correlated with Reasoning abilities (Figure 2B). The conjunction (at $p<0.001$ using

213 the conjunction null) between the spindle activation maps and the Reasoning-related spindle

214 correlation maps (Figure 2C), show several regions were consistently high and jointly activated

215 in both the spindle and Reasoning-spindle correlation maps, including the thalamus, medial

216 frontal cortex, bilateral putamen, and the cerebellum (Table 6).

Table 6. Conjunction between the spindle-related activation maps and the spindle-related activations correlated with reasoning abilities maps. (see Figure 2C)

\begin{tabular}{|c|c|c|c|c|c|c|}
\hline \multirow[b]{2}{*}{ Hemisphere } & \multirow[b]{2}{*}{ Region } & \multirow[b]{2}{*}{$\underline{x}$} & \multicolumn{2}{|c|}{ MNI Coordinate } & \multirow{2}{*}{$\begin{array}{l}\text { Peak z } \\
\text { score }\end{array}$} & \multirow{2}{*}{$\begin{array}{c}\text { FWE corrected } \\
\mathrm{p} \text {-value }\end{array}$} \\
\hline & & & $\mathbf{Y}$ & z & & \\
\hline Middle & anterior cingulate & -8 & 12 & 26 & 4.10 & $<0.001$ \\
\hline Middle & middle cingulate & -14 & 5 & 42 & 4.17 & $<0.001$ \\
\hline Left & putamen/pallidum & -16 & -6 & -2 & 4.39 & $<0.001$ \\
\hline Left & putamen & -32 & -10 & -4 & 3.75 & $<0.001$ \\
\hline Left & thalamus & -12 & -10 & 6 & 4.18 & $<0.001$ \\
\hline Right & thalamus & 12 & -10 & 8 & 4.00 & $<0.001$ \\
\hline Right & cerebellum & 14 & -64 & -34 & 3.80 & $<0.001$ \\
\hline
\end{tabular}

Note: Significant brain responses after Family Wise Error (FWE) correction $p<0.05$ at the clusterlevel.

Finally, to ensure that activations time-locked to spindles were specific to spindles per se, 
instead of onsets aligned to spindles events. The results revealed only a small single cluster at the left frontal lobe (peak coordinate: $-28,-2,68$; uncorrected $p<0.005$ ), which did not overlap with the activations time-locked to spindles (Figure S2), and did not survive correction for multiple comparisons, suggesting that this activation is non-specific to NREM sleep, and likely spurious. No correlation was observed between Reasoning ability and the uncorrected random onsets map. This suggests that the reactivations reported here, are specifically related to spindle events, and not simply to NREM sleep in general.

\section{DISCUSSION}

Sleep supports normal human cognitive performance, such as attention, language, reasoning, decision making, learning and memory (for review, see Alhola \& Polo-Kantola 2007; Diekelmann 2014; Diekelmann \& Born 2010; Goel et al. 2009; Harrison \& Horne 2000). Previous EEG studies have identified sleep spindles as a biological marker of cognitive abilities, and in particular, reasoning abilities (Bódizs et al., 2005; Fang et al., 2017; Fogel et al., 2007; Fogel \& Smith, 2011; Schabus et al., 2006; Ujma et al., 2014, 2015). Only a few EEG-fMRI studies have explored the brain activations correlated with sleep spindles (Andrade et al., 2011; Caporro et al., 2012; Laufs et al., 2007; Schabus et al., 2007; Tyvaert et al., 2008). Interestingly, some of these regions are also known to support reasoning abilities. However, the neuroanatomical functional correlates of the relationship between spindles and Reasoning abilities are unknown. Here, we identified the neural activation patterns time-locked to spindles that are correlated to cognitive abilities. Using a large sample of simultaneous EEG-fMRI sleep recordings, the results of the present study support three main findings: (1) similar to previous studies (Fang et al., 2017; Fogel et al., 2007), spindles detected at Cz (11-16Hz) during NREM sleep were related to Reasoning but not Short Term Memory or Verbal abilities, (2) similar to 
245 previous studies (Andrade et al., 2011; Caporro et al., 2012; Laufs et al., 2007; Schabus et al.,

246 2007; Tyvaert et al., 2008), activations time-locked to spindles were observed in the thalamus, 247 bilateral striatum, middle cingulate cortex, and cerebellum, and (3) Reasoning abilities were

correlated with spindle-related activations in a subset of these regions including the thalamus,

bilateral striatum, medial frontal gyrus, middle cingulate cortex, and precuneus. These results

are specific to spindles per se, and cannot be attributed to some epiphenomena during NREM

sleep; given that these results were not observed when random onsets during NREM sleep

were used instead of onsets time-locked to spindle events. Altogether, our results identified for

the first time, the neural correlates of the relationship between spindles and Reasoning abilities.

\section{Spindle-related activation of thalamocortical circuitry}

Consistent with previous EEG-fMRI studies of spindle-related activations (Andrade et al.,

2011; Caporro et al., 2012; Laufs et al., 2007; Schabus et al., 2007; Tyvaert et al., 2008), our

results identified and confirmed the brain regions associated with spindle events during NREM

sleep in both cortical (including the media prefrontal, anterior cingulate cortex, and middle

cingulate cortex), and subcortical areas (including the thalamus and bilateral caudate, putamen,

and pallidum), indicating the role of cortico-thalamic-basal ganglia circuitry in spindle generation.

In addition, positron emission tomography (PET) studies have shown changes in regional

neuroimaging findings are supported by a large body of animal studies, which at the cellular level, suggest that spindles reflect oscillatory activity in widespread thalamocortical circuits, and involve complex interactions between reticular, thalamocortical and pyramidal cells (Steriade, 2005). Classically, spindle generation was shown to be maintained by synchronized firing in the reticular-thalamocortical-reticular circuit (Steriade, Nunez, \& Amzica, 1993; von Krosigk et al., 
input initiates spindles by triggering spike bursts in the reticular nucleus and are terminated by desynchronization of thalamic and cortical neuronal firing. Thus, taken together, animal and recent human neuroimaging studies, including the current study, supports the involvement of thalamocortical circuitry in spindle generation.

The results of the current study identified a correlation between Reasoning, but not Short

Term Memory or Verbal abilities with spindle-related brain activations in thalamocortical

circuitry, especially the thalamus and the prefrontal cortex (PFC) region, which are thought to

be implicated in modulation of cognitive performance (Blair, 2006; Ferguson \& Gao, 2015;

Mitchell \& Chakraborty, 2013). Spindles and the thalamus have been shown to be related to human intellectual abilities (Fangmeier et al., 2006; Melrose et al., 2007). The thalamus, especially the mediodorsal thalamus has been reported to be related to the fluid intelligence (Van der Werf et al., 2003; Van Der Werf et al., 2000) particularly for the extrapolation component process of inductive reasoning (Jia et al., 2011; Liang et al., 2014) and other higherlevel cognition (e.g., problem solving, working memory, goal direct seeking) (Karatekin et al., 2000; Mitchell \& Chakraborty, 2013; Schiff et al., 2002; Shirvalkar et al., 2006). Lesions studies in both humans (De Witte et al., 2011; Kubat-Silman et al., 2002; Little et al., 2010) and nonhuman primates (for review, see Mitchell \& Chakraborty 2013) have revealed that thalamic damage impairs various broadly defined aspects of cognitive performance, including discrimination, memory, learning, attention and other neuropsychological behaviors. Other neuroanatomical studies (Bohlken et al., 2014) found that only thalamic volume was significantly correlated with general intellectual functioning. In addition, at least one study identified structural and functional abnormalities in the thalamus in adults with reduced 
suggesting that integrity and functioning of the neural circuitry involved in spindle generation support intellectual abilities, and in particular Reasoning abilities.

(Behrens et al., 2003), and the prefrontal-thalamic loop plays a critical role in various higher-

order cognitive processes, especially executive function (for reviews see Baxter 2013;

2012). A large body of literature has identified the role of the prefrontal cortex area in fluid

intelligence and Reasoning (Coricelli \& Nagel, 2009; Duncan, 2000; Gray et al., 2003; Melrose

et al., 2007; Sandman et al., 2014; Waltz et al., 1999). For example, patients with damage to

the prefrontal cortex exhibited a selective and catastrophic deficit for both deductive and

inductive reasoning tasks (Waltz et al., 1999). In addition, Gray et al., (2003) found that

individuals with higher fluid intelligence have greater activations in the prefrontal cortex.

Coricelli and Nagel (2009) have shown that reasoning abilities correlate with neural activity in

the medial prefrontal cortex. Additionally, at least one neuroanatomical MRI study employing

voxel-based morphometry has revealed a positive correlation between gray matter intensity in

the medial prefrontal cortex and reasoning abilities assessed by Cattell's Culture Fair Intelligence Test, and also the WAIS-R (Gong et al., 2005). Taken together, these findings suggest that the thalamus and prefrontal cortex region supports Reasoning abilities.

\section{Spindle-related activation of the basal ganglia}

Consistent with previous results (Caporro et al., 2012; Tyvaert et al., 2008), the present study shows that the basal ganglia, including striatal areas (caudate and putamen) and the globus pallidus were recruited during spindle events. The basal ganglia are primarily known for 
motor sequence learning, planning (Elsinger et al., 2006) and motor execution (Monchi et al.,

317 2006). In addition, several studies have observed robust activations in the basal ganglia for reasoning-related tasks compared to other cognitive tasks, including the caudate nucleus, putamen and globus pallidus (Ferguson \& Gao, 2015; Melrose et al., 2007; Rodriguez-Moreno \& Hirsch, 2009). Taken together, these findings complement the results of the current study whereby activation of the putamen time-locked spindles was correlated with Reasoning abilities.

The Reasoning subtests of the Cambridge Brain Sciences Trials, consists of tasks requiring planning (Shallice, 1982), spatial rotation (Silverman et al., 2000), and visuomotor ability

(Folstein et al., 1975). Sandman et al., (2014) has reported that the morphometry of the

putamen was associated with performance on reasoning-related subtests of the WAIS including

block design, matrix reasoning and perceptual index in preadolescent children. These findings suggest that the function and structure of the basal ganglia are related to Reasoning abilities.

The current study suggests that interindividual differences in spindle-related activation of these regions are related to Reasoning ability.

\section{Spindle-related activation of the cerebellum} activation of the cerebellum which was also correlated with Reasoning abilities. Many studies overlook cognition-related activity in the cerebellum, although this area is responsible for modulating thalamic activity through direct cerebello-thalamic projections, which may be related to spindle generation (Calzavara et al., 2005; Shouse \& Sterman, 1979). In addition, it has been suggested that the cerebellum supports cognitive functions (for reviews, see Gordon 2007;

Rapoport et al. 2000; Stoodley 2012) such as response reassignment during a complex task 
340

341

342

343

(Bellebaum \& Daum, 2007; Tomasi et al., 2007). Importantly, the cerebellum is activated during the deductive reasoning processing (Goel et al., 2000; Goel \& Dolan, 2004) supporting our finding that reasoning-related functions supported by the cerebellum is reflected during sleep, time-locked to spindles.

Unlike previous studies, we did not observe spindle-related activation of the medial temporal lobe (Andrade et al., 2011; Caporro et al., 2012; Laufs et al., 2007; Schabus et al., 2007; Tyvaert et al., 2008). In addition, Schabus et al., (2007) and Andrade et al. (2011) reported brain activation differences between fast spindles and slow spindles, particularly in hippocampal regions. However, here, we observed similar activation patterns for both spindle types and no significant differences between spindle types. However, we did find medial frontal activation for slow, but not fast spindle events. Despite having a large proportion of participants who slept for an adequate amount of NREM sleep, there may not have been an adequate number of each spindle type when categorized orthogonally for sufficient power, or perhaps not enough instersubject variability to detect any relationship to cognitive abilities. Moreover, sleep was recorded only from the first couple of hours of the night, where the relationship between Reasoning abilities and spindles has been found to be much less robust than the later part of the night (Fogel et al., 2007). This might also help explain that when separated into fast spindles and slow spindles, we did not observe significant relationship with Reasoning abilities in each spindle subtype. Lastly, due to the limited duration, and high intersubject variability of sleep in the scanner, we did not have sufficient SWS to test whether a different pattern of results was observed during SWS.

The clinical significance and applications of the relationship between spindles and cognitive abilities is yet to be realized. Deficient or dysfunctional spindle generation may be associated with compromised intellectual functioning. More specifically, it has been suggested 
364 that deficient gating mechanisms of thalamocortical circuitry (Bixler,1968) may explain

365 abnormal spindle production in children with mental disability (Gibbs \& Gibbs, 1962; Shibagaki

\& Kiyono, 1983). Moreover, the present study is an important first step which may lead to the

development of novel interventions utilizing spindle-enhancing neuromodulatory techniques

(e.g., neurofeedback, transcranial direct current stimulation, pharmacological) to improve

daytime cognitive performance and explore the physiological mechanisms which support the

function of sleep for memory and cognitive performance. Such an approach could target cognitive deficits, in cases where spindle production is abnormal such as in learning disabilities (Gibbs \& Gibbs, 1962; Shibagaki \& Kiyono, 1983), below normal cognitive functioning (Fogel \& Smith, 2011) , normal, healthy aging (Carrier et al., 2001; Fogel et al., 2014; Fogel et al., 2017), developmental disorders (Limoges et al., 2005) and in schizophrenia (Wamsley et al., 2012).

Here, we investigated what neural substrates support cognitive strengths and weaknesses. There are considerable interindividual differences in sleep spindles, which are very trait-like(Gaillard \& Blois, 1981; Silverstein \& Michael Levy, 1976). While the neural circuitry and generating mechanisms of spindles are well-understood, the neurophysiological basis of the relationship between spindles and cognitive abilities remain to be fully elucidated. In summary, our results show for the first time the neuroanatomical functional correlates of the relationship between sleep spindles and intellectual abilities. In particularly, our study found that the extent of the activation of the prefrontal cortex, basal ganglia, cerebellum and the thalamus time-locked to sleep spindles was correlated with interindividual differences in Reasoning, but not Verbal or STM abilities. Thus, spindles may serve as an electrophysiological marker of brain activations in regions which support the ability to employ reasoning to solve problems and apply logic in novel situations. 


\section{METHODS}

\section{Participants}

A total of 35 healthy right-handed adults (20 female) between $20-35$ years old $(M=25.6$,

SD = 3.6), were recruited to participate in this study. All participants were non-shift workers and

medication-free, had no history of head injury or seizures, had a normal body mass index $(<25)$,

and did not consume excessive caffeine, nicotine or alcohol. To be included, interested

participants had to score <10 on the Beck Depression (Beck et al., 1974) and the Beck Anxiety

(Beck et al., 1988) inventories and have no history or signs of sleep disorders indicated by the

Sleep Disorders Questionnaire (Douglass et al., 1994). All participants were required to keep a

regular sleep-wake cycle (bed-time between 22h00-24h00, wake-time between 07h00-09h00)

and to abstain from taking daytime naps at least 7 days prior to and throughout participation in

the study. Compliance with this schedule was assessed using both sleep diaries and wrist

actigraphy (Actiwatch 2, Philips Respironics, Andover, MA, USA) worn on the non-dominant

wrist. All participants met the MRI safety screening criteria. In addition, participants were given

a letter of information, provided informed written consent before participation, and were

financially compensated for their participation. This research was approved by the Western

University Health Science research ethics board.

Sample sizes were determined a-priori based on previous studies, and power calculated,

where possible using G*Power for Mac version 3.1 (Faul, Erdfelder, Buchner, \& Lang, 2009;

Faul, Erdfelder, Lang, \& Buchner, 2007). Based on the most comparable simultaneous EEG-

fMRI studies (Andrade et al., 2011; Caporro et al., 2012; Laufs et al., 2007; Schabus et al.,

2007; Tyvaert et al., 2008), previous studies have employed sample sizes $\mathrm{N}<15$. A recent study

by our group using the same cognitive tests as the current study (Fang et al., 2017) found 
412 replicating previous findings in smaller samples (e.g., $\mathrm{N}<12$ : Fogel et al., 2007; Fogel \& Smith, 413 2006). Based on power calculation for correlation with $p(2$-tailed $)=0.05(b=0.20$, effect size $=$ 414 0.56) from (Fang et al., 2017), an $\mathrm{N}=22$ was required. Thus, $\mathrm{N}=29$ subjects included in this study was considered to provide adequate statistical power for the main effects of interest.

416 Experimental procedure

Each participant underwent a screening/orientation session one week prior to the experimental sleep session. All participants completed the CBS test battery online at least 3 days prior to the experimental session. The experimental sleep session took place between 21h00 and 23h00, during which time simultaneous EEG-fMRI was recorded while participants slept in the scanner. To be included in the analyses, participants were required to sleep for a period of at least 5 minutes of uninterrupted NREM sleep during the sleep session. This was considered to be the minimum amount of data necessary for EEG and fMRI data analysis purposes, and to ensure a minimum duration, quality and continuity of sleep. It should be noted that all subjects had at least 14.67 minutes of sleep, with at least 63 total bandwidth spindles (11-16 Hz) at Cz. Importantly, the average duration of NREM sleep was 39.29 minutes, with an average of 334.74 total bandwidth spindles $(11-16 \mathrm{~Hz})$ at Cz. Following the sleep session, participants were allowed to sleep in the nearby sleep laboratory for the remainder of the night.

$432=23.97, \mathrm{SD}=3.83,17$ female) were included in the final data analyses.

\section{Cognitive ability test}


The Cambridge Brain Sciences test battery (Hampshire et al., 2012) was used to assess

participants' cognitive abilities. Cambridge Brain Sciences is a web-based battery of 12

cognitive tests that assesses a broad range of cognitive abilities including reasoning, problem

solving, planning, attention, and memory. A recent study, based on scores from a population-

sized pool of 44,600 participants, revealed three factors that govern performance across the

Cambridge Brain Sciences subtests. These factors have been described as "Reasoning",

"Short Term Memory" and "Verbal" ability (Hampshire et al., 2012). The descriptive statistics of

each subtest score are shown in Table 1.

\section{Polysomnographic Recording and Analysis}

Recording Parameters. EEG was recorded using a 64-channel magnetic resonance (MR)-

compatible EEG cap which included one electrocardiogram (ECG) lead (Braincap MR, Easycap,

Herrsching, Germany) and two MR-compatible 32-channel amplifiers (Brainamp MR plus, Brain

Products GmbH, Gilching, Germany). EEG caps included scalp electrodes referenced to FCz.

Two bipolar electrocardiogram (ECG) recordings were taken from V2-V5 and V3-V6 using an

MR-compatible 16-channel bipolar amplifier (Brainamp ExG MR, Brain Products GmbH,

Gilching, Germany). Using high-chloride abrasive electrode paste (Abralyt 2000 HiCL; Easycap, Herrsching, Germany), electrode-skin impedance was reduced to $<5 \mathrm{KOhm}$. To reduce movement-related EEG artifacts, participants' heads were immobilized in the MRI head-coil using foam cushions. EEG was digitized at 5000 samples per second with a 500-nV resolution. transferred via fiber optic cable to a personal computer where Brain Products Recorder 
bioRxiv preprint doi: https://doi.org/10.1101/130500; this version posted April 25, 2017. The copyright holder for this preprint (which was not

certified by peer review) is the author/funder, who has granted bioRxiv a license to display the preprint in perpetuity. It is made available under aCC-BY 4.0 International license.

458

correction

$$
\text { Sleep }
$$$$
\text { stages }
$$

were

scored

in

accordance

with

standard criteria (Iber et al., 2007) using the "VisEd Marks" toolbox (https://github.com/jade sjardins/vised_marks) for eeglab (Delorme \& Makeig, 2004). Automatic spindle detection was carried out using a previously published (Fogel et al., 2014; Fogel et al., 2015) and validated (Ray et al., 2015) method employing EEGlab-compatible (Delorme \& Makeig, 2004) software (github.com/stuartfogel/detect_spindles) written for MATLAB R2014a (The MathWorks Inc., Natick, MA). The detailed processing steps and procedures are reported elsewhere (Ray et al., 2015) and are thus presented only briefly here. The EEG data were initially downsampled to $250 \mathrm{~Hz}$. The detection was performed at Fz, Cz and Pz derivations. The spindle data were extracted from movement artifact-free, NREM stage 2 sleep epochs. The detection method (Ray et al., 2015) used a complex demodulation transformation of the EEG signal with a bandwidth of $5 \mathrm{~Hz}$ centered about a carrier frequency of $13.5 \mathrm{~Hz}$ (i.e., 11-16 Hz) (Iber et al., 2007). To utilize a fixed amplitude detection threshold, but still account for individual differences in spindles, each data point was transformed into a z-score using the mean and standard deviation derived from a 60 -sec sliding window. Events (spindle onsets, peaks, and offsets) were then detected on the transformed signal with a $z$-score threshold of $z=2.33$, corresponding to the $99^{\text {th }}$ percentile. The dependent variables of interest extracted from this method include spindle amplitude, spindle duration, and spindle density (number of spindles per minute of NREM sleep) for each participant and at each derivation ( $\mathrm{Fz}, \mathrm{Cz}$ and $\mathrm{Pz})$. Spindles were categorized so that they were orthogonal (non-overlapping detections) at the scalp locations where they predominate topographically (Jobert et al., 1992; Werth et al., 1997; Zeitlhofer et al., 1997) as slow spindles (11-13.5 Hz) at Fz, total bandwidth spindles (11-16 Hz) at $\mathrm{Cz}$, and fast spindles (13.5-16 Hz) at $\mathrm{Pz}$ (Table 2). Despite having no minimum detection 
481

\section{2}

483

484

485

486

criteria, the detection method employed here did not detect spindles lower than $0.2 \mathrm{sec}$, as found in a previous validation study (Ray et al., 2015).

\section{MRI Imaging Acquisition and Analysis}

Recording Parameters. Brain images were acquired using a 3.0T TIM TRIO magnetic resonance imaging system (Siemens, Erlangen, Germany) and a 64-channel head coil. In all participants, a structural T1-weighted MRI image was acquired using a 3D MPRAGE sequence $\left(\mathrm{TR}=2300 \mathrm{~ms}, \mathrm{TE}=2.98 \mathrm{~ms}, \mathrm{TI}=900 \mathrm{~ms}, \mathrm{FA}=9^{\circ}, 176\right.$ slices, FoV $=256 \times 256 \mathrm{~mm}^{2}$, matrix size $=256 \times 256 \times 176$, voxel size $=1 \times 1 \times 1 \mathrm{~mm}^{3}$ ). Multislice T2*-weighted fMRI images were acquired during the sleep session with a gradient echo-planar sequence using axial slice orientation $\left(\mathrm{TR}=2160 \mathrm{~ms}, \mathrm{TE}=30 \mathrm{~ms}, \mathrm{FA}=90^{\circ}, 40\right.$ transverse slices, $3 \mathrm{~mm}$ slice thickness, $10 \%$ inter-slice gap, FoV $=220 \times 220 \mathrm{~mm}^{2}$, matrix size $=64 \times 64 \times 40$, voxel size $=3.44 \times 3.44 \times 3$ $\mathrm{mm}^{3}$ ). Importantly, the sequence parameters were chosen so that the gradient artifact would be time stable, and the lowest harmonic of the gradient artifact $(18.52 \mathrm{~Hz})$ would occur outside the spindle band (11-16 Hz). This was achieved by setting the MR scan repetition time to 2160 $\mathrm{ms}$, such that it matched a common multiple of the EEG sample time $(0.2 \mathrm{~ms})$, the product of the scanner clock precision $(0.1 \mu \mathrm{s})$ and the number of slices (40 slices) used (Mulert \& Lemieux, 2009) .

\section{Image Preprocessing}

Functional images were preprocessed and analyzed using SPM8 (http://www.fil.ion.ucl.ac.uk/spm/software/spm8/; Welcome Department of Imaging Neuroscience, London, UK) implemented in MATLAB (ver. 8.5 R2015a) for Windows (Microsoft, Inc. Redmond, WA). Functional scans of each session were realigned using rigid body transformations, iteratively optimized to minimize the residual sum of squares between the first 
and each subsequent image separately for each session. A mean realigned image was then created from the resulting images. The structural T1-image was coregistered to this mean functional image using a rigid body transformation optimized to maximize the normalized mutual information between the two images. Coregistration parameters were then applied to the realigned blood-oxygen-level dependent (BOLD) time series. The coregistered structural images were segmented into grey matter, white matter and cerebrospinal fluid. An average subject-based template was created using DARTEL in SPM8. All functional and anatomical images were spatially normalized using the resulting template, which was generated from the structural scans. Finally, spatial smoothing was applied on all functional images (Gaussian kernel, $8 \mathrm{~mm}$ full-width at half-maximum (FWHM).

\section{Sleep sessions}

For data acquired during the simultaneous EEG-fMRI sleep recordings, within-session series of consecutive fMRI volumes sleep stage scored as NREM stage 2 sleep according to standard criteria (Iber et al., 2007) by an expert, registered polysomnographic technologist were selected from the complete fMRI time series of sleep session. To be included in the fMRI analysis, the EEG had to be visibly movement artifact-free and be a segment of uninterrupted sleep longer in duration than 55 volumes (i.e., $~ 120$ seconds or longer; corresponding to the minimum amount of sleep that was needed to perform the automated spindle detection), resulting in the inclusion of $36 \%$ of the total recorded data (i.e., 11,466 of $31,852 \mathrm{MRI}$ volumes during NREM stage 2 sleep). Each time series corresponding to NREM stage 2 sleep that met these criteria, were entered into the general linear model (GLM) as a separate session so that no gaps existed in the design matrix. For each participant, brain responses were estimated in an event-related design using a fixed-effects GLM including responses time-locked to spindle events $(11-16 \mathrm{~Hz})$ detected at $\mathrm{Cz}$, slow spindles (11-13.5 Hz) detected at Fz, and fast spindle 
events (13.5-16 Hz) detected at Pz. Consistent with similar previous studies (Andrade et al.,

2011; Bergmann et al., 2011; Dang-Vu et al., 2008; Schabus et al., 2007), the vectors, including

spindle events, were convolved with the canonical hemodynamic response function (HRF), as

well as with its temporal and dispersion derivatives. Nuisance variables in the model included:

the movement parameters estimated during realignment (translations in $\mathrm{x}, \mathrm{y}$, and $\mathrm{z}$ directions

and rotations around $x, y$, and $z$ axes), the squared value of the movement parameter, the first

derivative of each movement parameter, and the square of the first derivative of each

movement parameter, as well as, to the mean white matter intensity and the mean cerebral

spinal fluid intensity for each participant. Slow wave activity is a defining characteristic of NREM

sleep (Iber et al., 2007), but is related to spindle generation (Mölle et al., 2011; Siapas \& Wilson,

1998). This activity was accounted for by including spectral power $\left(\mu \mathrm{V}^{2}\right)$ in the delta band $(0.5$ -

$4 \mathrm{~Hz}$ ) for each TR window (2160 ms) as a variable of no interest, convolved with the

hemodynamic response function. Slow drifts were removed from the time series using a high

pass filter with a cut-off period of 128 seconds. Serial correlations in the fMRI signal were

estimated using an autoregressive (order 1) plus white noise model and a restricted maximum

likelihood (ReML) algorithm. These analyses generated statistical parametric t maps [(SPM(T)].

544 The resulting contrast images were then smoothed (FWHM $6 \mathrm{~mm}$ Gaussian Kernel) and entered into a second-level analysis. interest (i.e., all spindle events, fast spindle events, and slow spindle events). To investigate the relationship between the magnitude of the spindle-dependent activation and the cognitive abilities assessed by the CBS Trials, cognitive test scores for each subtest (i.e., Reasoning, Verbal, and Short Term Memory) were entered as covariates of interest in the described GLM. 
552

553

554

555

each contrast of interest. Statistical inferences were performed at a threshold of $p<0.05$, family wise error (FWE) corrected at the cluster level.

\section{Overlap between spindle-related maps and reasoning-spindle correlation maps}

To illustrate the overlap of activations between the spindle-related activation maps and reasoning-spindle correlation maps, the conjunction was taken as the minimum t-statistic using the conjunction hypothesis (Friston et al., 2005; Nichols et al., 2005) over: (1) a t-map testing for the main effect of the spindle events during the sleep session, and (2) a t-map testing for the main effect of the correlation between the Reasoning ability and spindle events. These two statistical maps were thresholded at $p<0.05$, FWE corrected at the cluster level.

Finally, to confirm that activations time-locked to spindles and correlated with Reasoning abilities were not simply an epiphenomenon of NREM sleep, we generated the same number of random events as sleep spindles in each segment of NREM sleep for all participants during the sleep session. These random onsets did not overlap with any spindle events. We conducted the exact same GLM as for actual spindle onsets, with the only difference being that the randomly generated onsets were included in the model, as opposed to the spindle onsets.

\section{ACKNOWLEDGEMENTS}

This research was funded by a Canada Excellence Research Chair (CERC) grant to author A.M.O. 
REFERENCE

575

576

577

578

579

580

581

582

583

584

585

586

587

588

589

590

591

592

593

594

595

596

597

598

599

600

601

602

603

604

605

606

607

608

609

610

611

612

613

614

Alhola, P., \& Polo-Kantola, P. (2007). Sleep deprivation: Impact on cognitive performance. Neuropsychiatric Disease and Treatment, 3(5), 553-567. https://doi.org/10.1016/j.smrv.2012.06.007

Andrade, K. C., Spoormaker, V. I., Dresler, M., Wehrle, R., Holsboer, F., Samann, P. G., \& Czisch, M. (2011). Sleep Spindles and Hippocampal Functional Connectivity in Human NREM Sleep. Journal of Neuroscience, 31(28), 10331-10339. https://doi.org/10.1523/JNEUROSCI.5660-10.2011

Baxter, M. G. (2013). Mediodorsal thalamus and cognition in non-human primates. Frontiers in Systems Neuroscience, 7(August), 38. https://doi.org/10.3389/fnsys.2013.00038

Beck, A. T., Rial, W. Y., \& Rickels, K. (1974). Short form of depression inventory: crossvalidation. Psychol Rep, 34(3), 1184-1186.

Beck, A. T., Steer, R. A., \& Carbin, M. G. (1988). Psychometric properties of the Beck Depression Inventory: Twenty-five years of evaluation. Clinical Psychology Review, 8(1), 77-100. https://doi.org/10.1016/0272-7358(88)90050-5

Behrens, T. E., Johansen-Berg, H., Woolrich, M. W., Smith, S. M., Wheeler-Kingshott, C. A., Boulby, P. A., Barker, G.J., Sillery, E.L., Sheehan, K., Ciccarelli, O., Thompson, A.J., Brady J.M., \& Matthews, P. M. (2003). Non-invasive mapping of connections between human thalamus and cortex using diffusion imaging. Nature Neuroscience, 6(7), 750-7. https://doi.org/10.1038/nn1075

Bellebaum, C., \& Daum, I. (2007). Cerebellar involvement in executive control. Cerebellum (London, England), 6(3), 184-192. https://doi.org/10.1080/14734220601169707

Bergmann, T. O., Mölle, M., Diedrichs, J., Born, J., \& Siebner, H. R. (2011). Sleep spindlerelated reactivation of category-specific cortical regions after learning face-scene associations. Neuroimage, 59(3), 2733-2742. Journal Article. https://doi.org/10.1016/j.neuroimage.2011.10.036

Bischoff-Grethe, A., Ivry, R. B., \& Grafton, S. T. (2002). Cerebellar involvement in response reassignment rather than attention. The Journal of Neuroscience: The Official Journal of the Society for Neuroscience, 22(2), 546-553. https://doi.org/22/2/546 [pii]

Bixler EO, R. J. (1968). Spindle activity during sleep in cultural-familial mild retardates. Psychophysiology, 5, 212.

Blackwood, N., Ffytche, D., Simmons, A., Bentall, R., Murray, R., \& Howard, R. (2004). The cerebellum and decision making under uncertainty. Cognitive Brain Research, 20(1), 4653. https://doi.org/10.1016/j.cogbrainres.2003.12.009

Blair, C. (2006). How similar are fluid cognition and general intelligence? A developmental neuroscience perspective on fluid cognition as an aspect of human cognitive ability. The Behavioral and Brain Sciences, 29(2006), 109-125-160. https://doi.org/10.1017/S0140525X06009034

Bódizs, R., Kis, T., Lázár, A. S., Havrán, L., Rigó, P., Clemens, Z., \& Halász, P. (2005). Prediction of general mental ability based on neural oscillation measures of sleep. Journal of Sleep Research, 14(3), 285-292. https://doi.org/10.1111/j.1365- 
Bódizs, R., Lázár, A. S., \& Rigó, P. (2008). Correlation of visuospatial memory ability with right parietal EEG spindling during sleep. Acta Physiologica Hungarica, 95(3), 297-306. https://doi.org/10.1556/APhysiol.95.2008.3.5

Bohlken, M. M., Brouwer, R. M., Mandl, R. C. W., van Haren, N. E. M., Brans, R. G. H., van Baal, G. C. M., de Geus, E.J.C., Boomsma, D.I., Kahn, R.S., \& Hulshoff Pol, H. E. (2014). Genes contributing to subcortical volumes and intellectual ability implicate the thalamus. Human Brain Mapping, 35(6), 2632-2642. https://doi.org/10.1002/hbm.22356

Bonjean, M., Baker, T., Lemieux, M., Timofeev, I., Sejnowski, T., \& Bazhenov, M. (2011). Corticothalamic feedback controls sleep spindle duration in vivo. J Neurosci, 31(25), 9124-9134. https://doi.org/10.1523/JNEUROSCI.0077-11.2011

Bugg, J. M., Zook, N. A., DeLosh, E. L., Davalos, D. B., \& Davis, H. P. (2006). Age differences in fluid intelligence: contributions of general slowing and frontal decline. Brain and Cognition, 62(1), 9-16. https://doi.org/10.1016/j.bandc.2006.02.006

Burgaleta, M., Macdonald, P. A., Martínez, K., Román, F. J., Álvarez-Linera, J., González, A. R., ... Colom, R. (2014). Subcortical regional morphology correlates with fluid and spatial intelligence. Human Brain Mapping, 35(5), 1957-1968. https://doi.org/10.1002/hbm.22305

Calzavara, R., Zappala, A., Rozzi, S., Matelli, M., \& Luppino, G. (2005). Neurochemical characterization of the cerebellar-recipient motor thalamic territory in the macaque monkey. European Journal of Neuroscience, 21(7), 1869-1894. Retrieved from http://cat.inist.fr/?aModele=afficheN\&cpsidt=16745682

Caporro, M., Haneef, Z., Yeh, H. J., Lenartowicz, A., Buttinelli, C., Parvizi, J., \& Stern, J. M. (2012). Functional MRI of sleep spindles and K-complexes. Clinical Neurophysiology, 123(2), 303-309. https://doi.org/10.1016/j.clinph.2011.06.018

Carrier, J., Land, S., Buysse, D. J., Kupfer, D. J., \& Monk, T. H. (2001). The effects of age and gender on sleep EEG power spectral density in the middle years of life (ages 20-60 years old). Psychophysiology, 38(2), 232-242.

Chakravarthy, V. S., Joseph, D., \& Bapi, R. S. (2010). What do the basal ganglia do? A modeling perspective. Biological Cybernetics, 103(3), 237-253. https://doi.org/10.1007/s00422-010-0401-y

Christoph Mulert, L. L., \& Christoph Mulert, L. L. (2010). EEG-fMRI: Physiological Basis, Technique and Applications (illustrate). Springer.

Clark, C. M., Li, D., Conry, J., Conry, R., \& Loock, C. (2000). Structural and functional brain integrity of fetal alcohol syndrome in nonretarded cases. Pediatrics, 105(5), 1096-1099. https://doi.org/10.1542/peds.105.5.1096

Coricelli, G., \& Nagel, R. (2009). Neural correlates of depth of strategic reasoning in medial prefrontal cortex. Proceedings of the National Academy of Sciences of the United States of America, 106(23), 9163-9168. https://doi.org/10.1073/pnas.0807721106

Dang-Vu, T. T., Schabus, M., Desseilles, M., Albouy, G., Boly, M., Darsaud, A., Gais,S., Rauchs, G., Sterpenich, V., Vandewalle, G., Carrier,J., Moonen, G., Balteau, E., 
Degueldre,C., Luxen, A., Phillips, C., \& Maquet, P. (2008). Spontaneous neural activity during human slow wave sleep. Proceedings of the National Academy of Science U S A, 105(39), 15160.

De Gennaro, L., Ferrara, M., Vecchio, F., Curcio, G., \& Bertini, M. (2005). An electroencephalographic fingerprint of human sleep. Neurolmage, 26(1), 114-122. https://doi.org/10.1016/j.neuroimage.2005.01.020

De Witte, L., Brouns, R., Kavadias, D., Engelborghs, S., De Deyn, P. P., \& Mariën, P. (2011). Cognitive, affective and behavioural disturbances following vascular thalamic lesions: A review. Cortex, 47(3), 273-319. https://doi.org/10.1016/j.cortex.2010.09.002

Delorme, A., \& Makeig, S. (2004). EEGLAB: An open source toolbox for analysis of singletrial EEG dynamics including independent component analysis. Journal of Neuroscience Methods, 134(1), 9-21. https://doi.org/10.1016/j.jneumeth.2003.10.009

Diekelmann, S. (2014). Sleep for cognitive enhancement. Front. Syst. Neurosci., 8(April). https://doi.org/10.3389/fnsys.2014.00046

Diekelmann, S., \& Born, J. (2010). The memory function of sleep. Nature Reviews Neuroscience, 11(2), 114-126. https://doi.org/10.1038/nrn2762

Douglass, A. B., Bornstein, R., Nino-Murcia, G., Keenan, S., Miles, L., Zarcone Jr, V. P., Guilleminault, C., \& Dement, W. C. (1994). The Sleep Disorders Questionnaire. I: Creation and multivariate structure of SDQ. Sleep, 17(2), 160.

Doyon, J., Bellec, P., Amsel, R., Penhune, V., Monchi, O., Carrier, J., Lehéricy, S., \& Benali, $H$. (2009). Contributions of the basal ganglia and functionally related brain structures to motor learning. Behavioural Brain Research, 199(1), 61-75. https://doi.org/10.1016/j.bbr.2008.11.012

Duncan, J. (2000). A Neural Basis for General Intelligence. Science, 289(5478), 457-460. https://doi.org/10.1126/science.289.5478.457

Elsinger, C. L., Harrington, D. L., \& Rao, S. M. (2006). From preparation to online control: reappraisal of neural circuitry mediating internally generated and externally guided actions. Neurolmage, 31(3), 1177-87. https://doi.org/10.1016/j.neuroimage.2006.01.041

Fang, Z., Sergeeva, V., Ray, L. B., Viczko, J., Owen, A. M., \& Fogel, S. M. (2017). Sleep Spindles and Intellectual Ability: Epiphenomenon or Directly Related? Journal of Cognitive Neuroscience, 29, 167-182. https://doi.org/10.1162/jocn

Fangmeier, T., Knauff, M., Ruff, C. C., \& Sloutsky, V. (2006). fMRI Evidence for a ThreeStage Model of Deductive Reasoning, 320-334.

Faul, F., Erdfelder, E., Buchner, A., \& Lang, A.G. (2009). Statistical power analyses using G*Power 3.1: tests for correlation and regression analyses. Behavior Research Methods, 41(4), 1149-60. https://doi.org/10.3758/BRM.41.4.1149

Faul, F., Erdfelder, E., Lang, A.G., \& Buchner, A. (2007). GPOWER: A general power analysis program. Behavior Research Methods, 39(2), 175-191. https://doi.org/10.3758/BF03193146

Ferguson, B. R., \& Gao, W.J. (2015). Development of thalamocortical connections between 
the mediodorsal thalamus and the prefrontal cortex and its implication in cognition. Frontiers in Human Neuroscience, 8, 1027. https://doi.org/10.3389/fnhum.2014.01027

Fogel, S. M., Albouy, G., Vien, C., Popovicci, R., King, B. R., Hoge, R. D., Jbabdi, S., Habib, B., Karni, A., Maquet, P., \& Doyon, J. (2014). fMRI and sleep correlates of the agerelated impairment in motor memory consolidation. Hum Brain Mapp, 35(8), 3625-3645. https://doi.org/10.1002/hbm.22426

Fogel, S. M., Ray, L. B., Binnie, L., \& Owen, A. M. (2015). How to become an expert: A new perspective on the role of sleep in the mastery of procedural skills. Neurobiology of Learning and Memory, 125, 236-248. https://doi.org/10.1016/j.nlm.2015.10.004

Fogel, S. M., \& Smith, C. T. (2011). The function of the sleep spindle: A physiological index of intelligence and a mechanism for sleep-dependent memory consolidation. Neuroscience and Biobehavioral Reviews, 35(5), 1154-1165. https://doi.org/10.1016/j.neubiorev.2010.12.003

Fogel, S., Nader, R. S., Cote, K. A., \& Smith, C. (2007). Sleep spindles and learning potential. Behavioral Neuroscience, 121(1), 1-10. https://doi.org/10.1037/0735-7044.121.1.1

Fogel, S., \& Smith, C. T. (2006). Learning-dependent changes in sleep spindles and Stage 2 sleep. Journal of Sleep Research, 15(3), 250-255. https://doi.org/10.1111/j.13652869.2006.00522.x

Fogel, S., Vien, C., Karni, A., Benali, H., Carrier, J., \& Doyon, J. (2017). Sleep spindles: a physiological marker of age-related changes in gray matter in brain regions supporting motor skill memory consolidation. Neurobiology of Aging, 49, 154-164. https://doi.org/10.1016/j.neurobiolaging.2016.10.009

Folstein, M. F., Folstein, S. E., \& McHugh, P. R. (1975). "Mini-mental state": a practical method for grading the cognitive state of patients for the clinician. Journal of Psychiatric Research, 12(3), 189-198. https://doi.org/10.1016/0022-3956(75)90026-6

Friston, K., Penny, W., \& Glaser, D. E. (2005). Conjunction revisited. Neuroimage, 25(3), 661-667. Journal Article. https://doi.org/10.1016/j.neuroimage.2005.01.013

Funahashi, S. (2013). Thalamic mediodorsal nucleus and its participation in spatial working memory processes: comparison with the prefrontal cortex. Frontiers in Systems Neuroscience, 7(JUL), 36. https://doi.org/10.3389/fnsys.2013.00036

Gaillard, J. M., \& Blois, R. (1981). Spindle density in sleep of normal subjects. Sleep, 4(4), 385-91. Retrieved from http://www.ncbi.nlm.nih.gov/pubmed/7313391

Gibbs, E. L., \& Gibbs, F. A. (1962). Extreme spindles: correlation of electroencephalographic sleep pattern with mental retardation. Science, 138, 1106-1107.

Goel, N., Rao, H., Durmer, J. S., \& Dinges, D. F.(2009). Neurocognitive consequences of sleep deprivation. Seminars in Neurology, 29(4), 320-39. https://doi.org/10.1055/s-00291237117

Goel, V., Buchel, C., Frith, C., \& Dolan, R. J. (2000). Dissociation of mechanisms underlying syllogistic reasoning. Neurolmage, 12(5), 504-14.

https://doi.org/10.1006/nimg.2000.0636 
Goel, V., \& Dolan, R. J. (2004). Differential involvement of left prefrontal cortexin inductive and deductive reasoning. Cognition, 93(3).

https://doi.org/10.1016/j.cognition.2004.03.001

Gong, Q. Y., Sluming, V., Mayes, A., Keller, S., Barrick, T., Cezayirli, E., \& Roberts, N. (2005). Voxel-based morphometry and stereology provide convergent evidence of the importance of medial prefrontal cortex for fluid intelligence in healthy adults. Neurolmage, 25(4), 1175-1186. https://doi.org/10.1016/j.neuroimage.2004.12.044

Gordon, N. (2007). The cerebellum and cognition. European Journal of Paediatric Neurology, 11(4), 232-234. https://doi.org/10.1016/j.ejpn.2007.02.003

Gray, J. R., Chabris, C. F., \& Braver, T. S. (2003). Neural mechanisms of general fluid. Nature Neuroscience, 6(3), 316-322. https://doi.org/10.1038/nn1014

Hampshire, A., Highfield, R. R., Parkin, B. L., \& Owen, A. M. (2012). Fractionating human intelligence. Neuron, 76(6), 1225-1237. https://doi.org/10.1016/j.neuron.2012.06.022

Harrison, Y., \& Horne, J. A. (2000). The impact of sleep deprivation on decision making: a review. Journal of Experimental Psychology. Applied, 6(3), 236-49.

Hofle, N., Paus, T., Reutens, D., Fiset, P., Gotman, J., Evans, A. C., \& Jones, B. E. (1997). Regional Cerebral Blood Flow Changes as a Function of Delta and Spindle Activity during Slow Wave Sleep in Humans. J. Neurosci., 17(12), 4800-4808.

Iber, C., Ancoli-Israel, S., Chesson, A. L., \& Quan, S. F. (2007). The AASM manual for the scoring of sleep and associated events: rules, terminology and technical specifications. American Academy of Sleep Medicine, Westchester, IL. American Academy of Sleep Medicine Westchester, IL.

Jia, X., Liang, P., Lu, J., Yang, Y., Zhong, N., \& Li, K. (2011). Common and dissociable neural correlates associated with component processes of inductive reasoning. Neurolmage, 56(4), 2292-2299. https://doi.org/10.1016/j.neuroimage.2011.03.020

Jobert, M., Poiseau, E., Jahnig, P., Schulz, H., \& Kubicki, S. (1992). Topographical analysis of sleep spindle activity. Neuropsychobiology, 26(4), 210-217. https://doi.org/118923

Karatekin, C., Lazareff, J. A., \& Asarnow, R. F. (2000). Relevance of the cerebellar hemispheres for executive functions. Pediatric Neurology, 22(2), 106-112. https://doi.org/10.1016/S0887-8994(99)00128-9

Krakauer, J. W., \& Mazzoni, P. (2011). Human sensorimotor learning: Adaptation, skill, and beyond. Current Opinion in Neurobiology, 21(4), 636-644. https://doi.org/10.1016/j.conb.2011.06.012

Kroger, J. K. (2002). Recruitment of Anterior Dorsolateral Prefrontal Cortex in Human Reasoning: a Parametric Study of Relational Complexity. Cerebral Cortex, 12(5), 477485. https://doi.org/10.1093/cercor/12.5.477

Kubat-Silman, A. K., Dagenbach, D., \& Absher, J. R. (2002). Patterns of impaired verbal, spatial, and object working memory after thalamic lesions. Brain and Cognition, 50(2), 178-193. https://doi.org/10.1016/S0278-2626(02)00502-X

Laufs, H., Walker, M. C., \& Lund, T. E. (2007). "Brain activation and hypothalamic functional 
connectivity during human non-rapid eye movement sleep: an EEG/fMRI study"--its limitations and an alternative approach. Brain: A Journal of Neurology, 130(Pt 7), e75; author reply e76. https://doi.org/10.1093/brain/awm084

Leisman, G., Braun-Benjamin, O., \& Melillo, R. (2014). Cognitive-motor interactions of the basal ganglia in development. Frontiers in Systems Neuroscience, 8(February), 16. https://doi.org/10.3389/fnsys.2014.00016

Liang, P., Jia, X., Taatgen, N. A., Zhong, N., \& Li, K. (2014). Different strategies in solving series completion inductive reasoning problems: An fMRI and computational study. International Journal of Psychophysiology, 93(2), 253-260. https://doi.org/10.1016/j.ijpsycho.2014.05.006

Limoges, E., Mottron, L., Bolduc, C., Berthiaume, C., \& Godbout, R. (2005). Atypical sleep architecture and the autism phenotype. Brain, 128(5), 1049-1061.

https://doi.org/10.1093/brain/awh425

Little, D. M., Kraus, M. F., Joseph, J., Geary, E. K., Susmaras, T., Zhou, X. J., Pliskin, N., \& Gorelick, P. B. (2010). Thalamic integrity underlies executive dysfunction in traumatic brain injury. Neurology, 74(7), 558-564. https://doi.org/10.1212/WNL.0b013e3181cff5d5

Logan, C. G., \& Grafton, S. T. (1995). Functional anatomy of human eyeblink conditioning determined with regional cerebral glucose metabolism and positron-emission tomography. PNAS: Proceedings of the National Academy of Sciences of the United States of America, 92(16), 7500-7504. https://doi.org/10.1073/pnas.92.16.7500

Melrose, R. J., Poulin, R. M., \& Stern, C. E. (2007). An fMRI investigation of the role of the basal ganglia in reasoning. Brain Research, 2, 146-158. https://doi.org/10.1016/j.brainres.2007.01.060

Mitchell, A. S., \& Chakraborty, S. (2013). What does the mediodorsal thalamus do? Frontiers in Systems Neuroscience, 7(August), 37. https://doi.org/10.3389/fnsys.2013.00037

Mölle, M., Bergmann, T. O., Marshall, L., \& Born, J. (2011). Fast and Slow Spindles during the Sleep Slow Oscillation: Disparate Coalescence and Engagement in Memory Processing. Sleep, 34, 1411-1421. https://doi.org/10.5665/sleep.1290

Monchi, O., Petrides, M., Strafella, A. P., Worsley, K., \& Doyon, J. (2006). Functional role of the basal ganglia in the planning and execution of actions. Ann Neurol, 59(2), 257-264. https://doi.org/10.1002/ana.20742

Nader, R. S., \& Smith, C. (2001). The relationship between stage 2 sleep spindles and intelligence. Sleep, 24, A160.

Nader, R. S., \& Smith, C. (2003). A role for Stage 2 sleep in memory processing. Sleep and Brain Plasticity, 1(9), 87-99.

Nichols, T., Brett, M., Andersson, J., Wager, T., \& Poline, J. B. (2005). Valid conjunction inference with the minimum statistic. Neuroimage, 25(3), 653-660. Journal Article. https://doi.org/10.1016/j.neuroimage.2004.12.005

O'Doherty, J. P. (2004). Reward representations and reward-related learning in the human brain: Insights from neuroimaging. Current Opinion in Neurobiology, 14(6), 769-776. https://doi.org/10.1016/j.conb.2004.10.016 
Rapoport, M., Reekum, R. Van, \& Mayberg, H. (2000). The Role of the Cerebellum in Cognition and Behavior: A Selective Review. Journal Of Neuropsychiatry, 193-198. https://doi.org/10.1176/appi.neuropsych.12.2.193

Raven, J. C., Court, J. H. and Raven, J. (1976). Manual for Raven's Progressive Matrices.

Ray, L. B., Sockeel, S., Soon, M., Bore, A., Myhr, A., Stojanoski, B., Cusack, R., Owen, A.M., Doyon, J., \& Fogel, S. (2015). Expert and crowd-sourced validation of an individualized sleep spindle detection method employing complex demodulation and individualized normalization. Frontiers in Human Neuroscience, 9(9), 507. https://doi.org/10.3389/fnhum.2015.00507

Rechtschaffen, A.Kales, A. (1968). Manual of Standardized Terminology, Techniques and Scoring System for Sleep Stages of Human Subjects. UCLA Brain Information Service/Brain Research Institute, Los Angeles, 1968.

Rodriguez-Moreno, D., \& Hirsch, J. (2009). The dynamics of deductive reasoning: An fMRI investigation. Neuropsychologia, 47(4), 949-961. https://doi.org/10.1016/j.neuropsychologia.2008.08.030

Sandman, C. A., Head, K., Muftuler, L. T., Su, L., Buss, C., \& Poggi, E. (2014). Neurolmage Shape of the basal ganglia in preadolescent children is associated with cognitive performance. Neurolmage, 99, 93-102. https://doi.org/10.1016/j.neuroimage.2014.05.020

Schabus, M., Dang-Vu, T. T., Albouy, G., Balteau, E., Boly, M., Carrier, J., Darsaud, A., Degueldre, C., Desseilles, M., Gais, S., Phillips, C., Rauchs, G., Schnakers, C., Sterpenich, V., Vandewalle, G., Luxen, A., \& Maquet, P. (2007). Hemodynamic cerebral correlates of sleep spindles during human non-rapid eye movement sleep. Proceedings of the National Academy of Sciences of the United States of America, 104(32), 1316413169. https://doi.org/10.1073/pnas.0703084104

Schabus, M., Hödlmoser, K., Gruber, G., Sauter, C., Anderer, P., Klösch, G., Parapatics, S., Saletu, B., Klimesch, W., \& Zeitlhofer, J. (2006). Sleep spindle-related activity in the human EEG and its relation to general cognitive and learning abilities. European Journal of Neuroscience, 23(7), 1738-1746. https://doi.org/10.1111/j.1460-9568.2006.04694.x

Schiff, N. D., Plum, F., \& Rezai, A. R. (2002). Developing prosthetics to treat cognitive disabilities resulting from acquired brain injuries. Neurological Research, 24(February), 116-124. https://doi.org/10.1179/016164102101199576

Shallice, T. (1982). Specific Impairments of Planning. Philosophical Transactions of the Royal Society B: Biological Sciences, 298(1089), 199-209. https://doi.org/10.1098/rstb.1982.0082

Shibagaki, M., \& Kiyono, S. (1983). Duration of spindle bursts during nocturnal sleep in mentally retarded children. Electroencephalography and Clinical Neurophysiology, 55(6), 645-651. http://doi.org/10.1016/0013-4694(83)90274-2

Shibagaki, M., Kiyono, S., \& Watanabe, K. (1982). Spindle evolution in normal and mentally retarded children: a review. Sleep, 5(1), 47-57.

Shirvalkar, P., Seth, M., Schiff, N. D., \& Herrera, D. G. (2006). Cognitive enhancement with 
central thalamic electrical stimulation. Proceedings of the National Academy of Sciences of the United States of America, 103(45), 17007-17012.

https://doi.org/10.1073/pnas.0604811103

Shouse, M. N., \& Sterman, M. B. (1979). Changes in seizure susceptibility, sleep time and sleep spindles following thalamic and cerebellar lesions. Electroencephalography and Clinical Neurophysiology, 46(1), 1-12. https://doi.org/10.1016/0013-4694(79)90044-0

Siapas, A. G., \& Wilson, M. A. (1998). Coordinated interactions between hippocampal ripples and cortical spindles during slow-wave sleep. Neuron, 21(5), 1123-1128. https://doi.org/10.1016/S0896-6273(00)80629-7

Silverman, I., Choi, J., Mackewn, A., Fisher, M., Moro, J., \& Olshansky, E. (2000). Evolved mechanisms underlying wayfinding. Evolution and Human Behavior, 21(3), 201-213. https://doi.org/10.1016/S1090-5138(00)00036-2

Silverstein, L. D., \& Michael Levy, C. (1976). The stability of the sigma sleep spindle. Electroencephalography and Clinical Neurophysiology, 40(6), 666-670. https://doi.org/10.1016/0013-4694(76)90142-5

Steriade, M. (2005). Sleep, epilepsy and thalamic reticular inhibitory neurons. Trends Neurosci, 28(6), 317-324. https://doi.org/10.1016/j.tins.2005.03.007

Steriade, M., Contreras, D., Curro Dossi, R., \& Nunez, A. (1993). The slow (<1 Hz) oscillation in reticular thalamic and thalamocortical neurons: scenario of sleep rhythm generation in interacting thalamic and neocortical networks. Journal of Neuroscience, 13(8), 3284.

Steriade, M., McCormick, D. A., \& Sejnowski, T. J. (1993). Thalamocortical oscillations in the sleeping and aroused brain. Science (New York, N.Y.), 262(5134), 679-85. https://doi.org/10.1126/science.8235588

Steriade, M., Nunez, A., \& Amzica, F. (1993). A novel slow (<1 Hz) oscillation of neocortical neurons in vivo: depolarizing and hyperpolarizing components. Journal of Neuroscience, 13(8), 3252.

Stoodley, C. J. (2012). The cerebellum and cognition: Evidence from functional imaging studies. Cerebellum, 11(2), 352-365. https://doi.org/10.1007/s12311-011-0260-7

Tomasi, D., Chang, L., Caparelli, E. C., \& Ernst, T. (2007). Different activation patterns for working memory load and visual attention load. Brain Research, 1132(1), 158-165. https://doi.org/10.1016/j.brainres.2006.11.030

Tyvaert, L., Levan, P., Grova, C., Dubeau, F., \& Gotman, J. (2008). Clinical Neurophysiology Effects of fluctuating physiological rhythms during prolonged EEG-fMRI studies. Clinical Neurophysiology, 119(12), 2762-2774. https://doi.org/10.1016/j.clinph.2008.07.284

Ujma, P. P., Bódizs, R., Gombos, F., Stintzing, J., Konrad, B. N., Genzel, L., Steiger, A., \& Dresler, M. (2015). Nap sleep spindle correlates of intelligence. Scientific Reports, 5, 17159. https://doi.org/10.1038/srep17159

Ujma, P. P., Konrad, B. N., Genzel, L., Bleifuss, A., Simor, P., Pótári, A., Körmendi, J., Gombos, F., Steiger, A., Bódizs, R., \& Dresler, M. (2014). Sleep spindles and intelligence: evidence for a sexual dimorphism. J Neurosci, 34(49), 16358-16368. https://doi.org/10.1523/JNEUROSCI.1857-14.2014 
Van der Werf, Y. D., Jolles, J., Witter, M. P., \& Uylings, H. B. M. (2003). Contributions of thalamic nuclei to declarative memory functioning. Cortex; a Journal Devoted to the Study of the Nervous System and Behavior, 39(4-5), 1047-62. https://doi.org/10.1016/S0010-9452(08)70877-3

Van Der Werf, Y. D., Witter, M. P., Uylings, H. B. M., \& Jolles, J. (2000). Neuropsychology of infarctions in the thalamus: A review. Neuropsychologia, 38(5), 613-627. https://doi.org/10.1016/S0028-3932(99)00104-9

von Krosigk, M., Bal, T., \& McCormick, D. A. (1993). Cellular mechanisms of a synchronized oscillation in the thalamus. Science, 261(5119), 361-364.

Waltz, J. A., Knowlton, B. J., Holyoak, K. J., Boone, K. B., Mishkin, F. S., de Menezes Santos, M., Thomas, C.R., \&Miller, B. L. (1999). A System for Relational Reasoning in Human Prefrontal Cortex. Psychological Science, 10(August 2015), 119-125. https://doi.org/10.1111/1467-9280.00118

Wamsley, E. J., Tucker, M. A., Shinn, A. K., Ono, K. E., McKinley, S. K., Ely, A. V, ... Manoach, D. S. (2012). Reduced sleep spindles and spindle coherence in schizophrenia: mechanisms of impaired memory consolidation? Biological Psychiatry, 71(2), 154-61. https://doi.org/10.1016/j.biopsych.2011.08.008

Watanabe, Y., \& Funahashi, S. (2012). Thalamic mediodorsal nucleus and working memory. Neuroscience and Biobehavioral Reviews, 36(1), 134-142. https://doi.org/10.1016/j.neubiorev.2011.05.003

Wecshler, D. (1997). Wechsler Adult Intelligence Scale-III. The Psychological Corporation. San Antonio, TX.

Werth, E., Achermann, P., Dijk, D. J., \& Borbely, A. A. (1997). Spindle frequency activity in the sleep EEG: individual differences and topographic distribution. Electroencephalography and Clinical Neurophysiology, 103(5), 535-542. https://doi.org/S0013469497000709 [pii]

Zeitlhofer, J., Gruber, G., Anderer, P., Asenbaum, S., Schimicek, P., \& Saletu, B. (1997). Topographic distribution of sleep spindles in young healthy subjects. Journal of Sleep Research, 6(3), 149-155. 
bioRxiv preprint doi: https://doi.org/10.1101/130500; this version posted April 25, 2017. The copyright holder for this preprint (which was not certified by peer review) is the author/funder, who has granted bioRxiv a license to display the preprint in perpetuity. It is made available under aCC-BY 4.0 International license.

Figure S1. Cerebral activation of fast and slow spindles. Activations time-locked to fast spindles (13.5-16 Hz) at $\mathrm{Pz}(\mathbf{A})$ and slow spindles $(11-13.5 \mathrm{~Hz})$ at $\mathrm{Fz}(\mathbf{B})$ were similar in all brain areas, but visibly to a greater extent in fast spindles (with the exception of medial frontal activation in slow but not fast spindles). However, there were no significant difference between fast spindles vs. slow spindle-related activations.

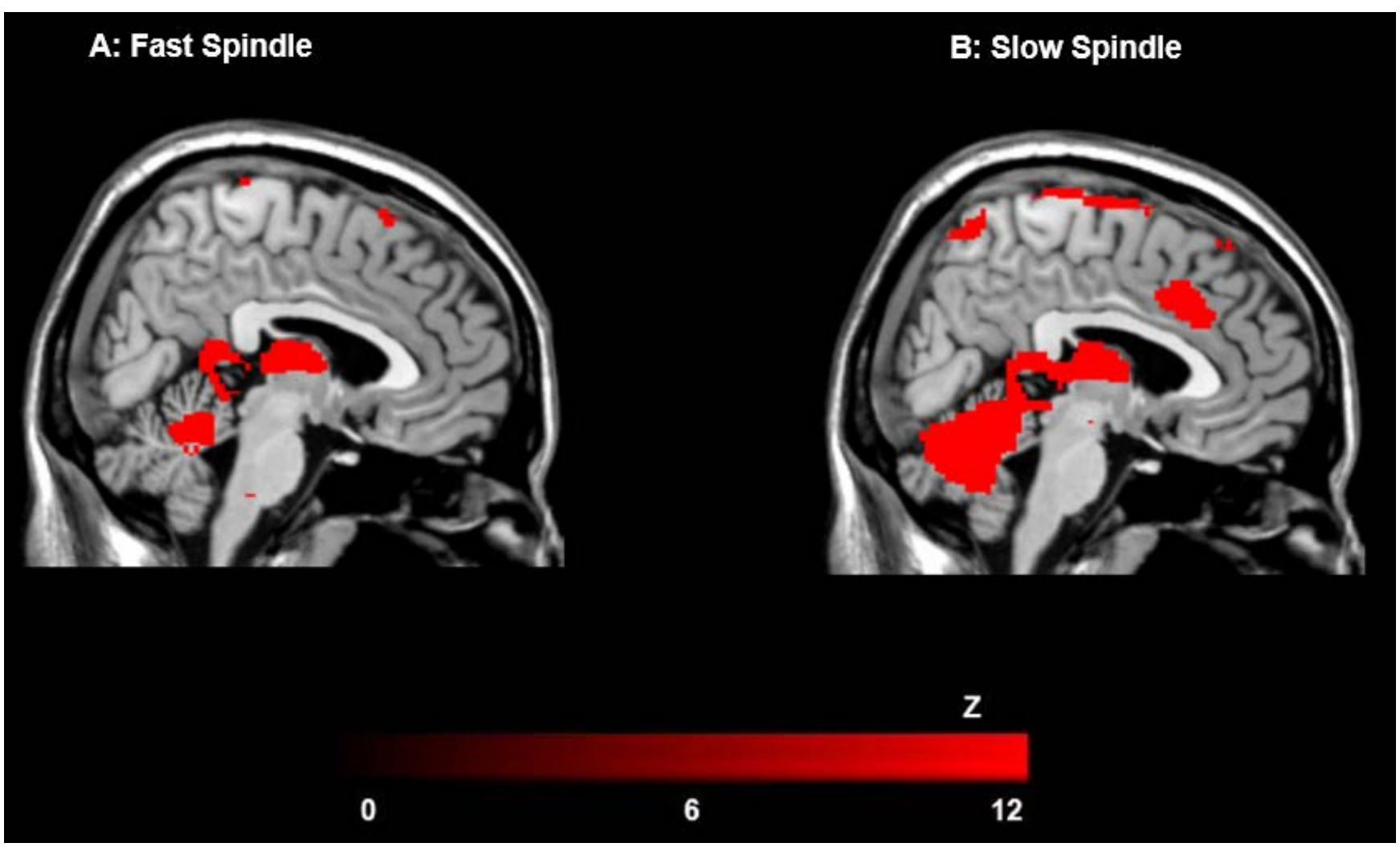




\section{A: Random onsets activation}
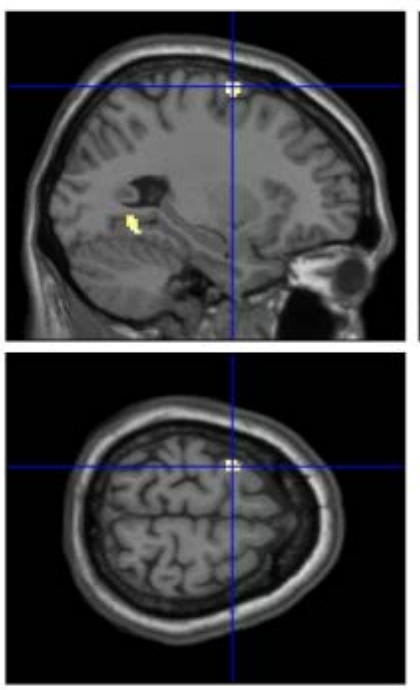
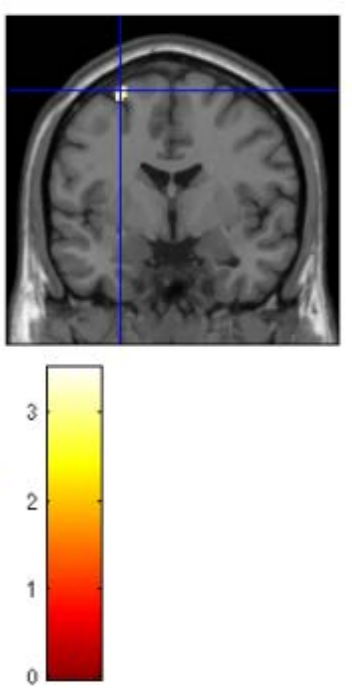

\section{B: Sleep spindle activation}
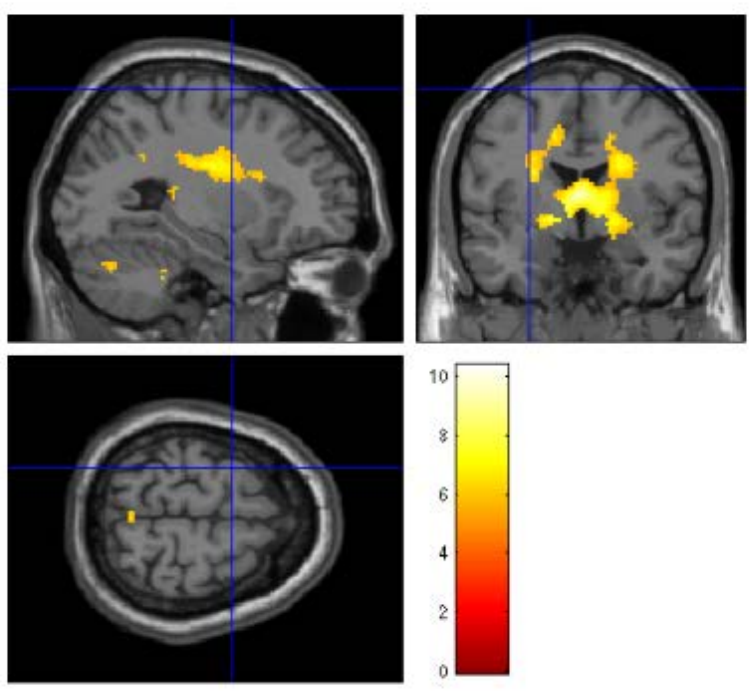

Figure S2. Cerebral activations time-locked to random onsets in NREM stage sleep. The results revealed a small single cluster at left frontal lobe which did not survive FWE correction (peak coordinate: -28, -2, 68; uncorrected $p<0.005)(A)$, and did not overlap with activations time-locked to spindles $(B)$. 